CLINICAL ETHICS

\title{
Internists' attitudes towards terminal sedation in end of life care
}

\author{
L C Kaldjian, J F Jekel, J L Bernene, G E Rosenthal, M Vaughan-Sarrazin, T P Duffy
}

J Med Ethics 2004;30:499-503. doi: 10.1136/jme.2003.004895

See end of article for authors' affiliations

Correspondence to:

L C Kaldjian, Department of Internal Medicine,

University of lowa Carver

College of Medicine, 200

Hawkins Drive, lowa City,

IA 52242, USA;

lauris-kaldjian@uiowa.edu

Received 19 May 2003

In revised form

3 September 2003

Accepted for publication

24 September 2003

\begin{abstract}
Objective: To describe the frequency of support for terminal sedation among internists, determine whether support for terminal sedation is accompanied by support for physician assisted suicide (PAS), and explore characteristics of internists who support terminal sedation but not assisted suicide.

Design: A statewide, anonymous postal survey.

Setting: Connecticut, USA.

Participants: 677 Connecticut members of the American College of Physicians.

Measurements: Attitudes toward terminal sedation and assisted suicide; experience providing primary care to terminally ill patients; demographic and religious characteristics.

Results: $78 \%$ of respondents believed that if a terminally ill patient has intractable pain despite aggressive analgesia, it is ethically appropriate to provide terminal sedation (diminish consciousness to halt the experience of pain). Of those who favoured terminal sedation, $38 \%$ also agreed that PAS is ethically appropriate in some circumstances. Along a three point spectrum of aggressiveness in end of life care, the plurality of respondents (47\%) were in the middle, agreeing with terminal sedation but not with PAS. Compared with respondents who were less aggressive or more aggressive, physicians in this middle group were more likely to report having more experience providing primary care to terminally ill patients $(p=0.02)$ and attending religious services more frequently $(p<0.001)$.

Conclusions: Support for terminal sedation was widespread in this population of physicians, and most who agreed with terminal sedation did not support PAS. Most internists who support aggressive palliation appear likely to draw an ethical line between terminal sedation and assisted suicide.
\end{abstract}

A dvocates of palliative care emphasise the availability of aggressive interventions that can alleviate even the most intolerable and intractable symptoms at the end of life. ${ }^{12}$ One such intervention is terminal sedation, in which the alleviation of a dying patient's refractory symptomssuch as pain, dyspnea, delirium, or nausea-are treated with symptom specific therapies that may have sedation as a side effect or are controlled by intentionally inducing sedation..$^{3-6}$ Although there is debate about terminology ${ }^{17-9}$ and whether or not a hastened death is intended, ${ }^{6}{ }^{10-12}$ terminal sedation has an established place among palliative care providers as a necessary option of last resort ${ }^{12713}$ and its prevalence in hospice care has been documented. ${ }^{14-19}$ The medical and ethical legitimacy of terminal sedation has been assessed in discussions regarding aggressive palliative care, ${ }^{28}$ the principle of double effect, ${ }^{20}$ and physician assisted suicide (PAS). ${ }^{21}{ }^{22}$ Its clinical necessity and ethical justification have also received support from the United States Supreme Court. ${ }^{23-26}$

Despite considerable discussion about terminal sedation in the literature, there has been very little empirical investigation of physician attitudes toward this practice. ${ }^{27}$ We are aware of a report that $89 \%$ of 53 palliative care physicians agreed that terminal sedation was sometimes necessary, ${ }^{1}$ and we found that $66 \%$ of 236 medical house officers in Connecticut agreed that it is ethically appropriate to provide terminal sedation to treat intractable pain associated with terminal illness. ${ }^{28}$ Given the interest that patients, their families, and professionals have in the availability of aggressive palliation for terminally ill patients with refractory symptoms, there is a need to document attitudes toward terminal sedation among physicians who care for patients at the end of life. ${ }^{21}$ We surveyed internists to: (1) determine the frequency of physician support for terminal sedation in end of life care; (2) determine whether physicians who support terminal sedation also support physician assisted suicide, and (3) explore characteristics of physicians who support terminal sedation but not assisted suicide.

\section{METHODS}

\section{Survey instrument}

Following a review of literature regarding palliative care and PAS, a survey instrument was designed that included questions pertaining to aggressive palliative analgesia, terminal sedation, and assisted suicide (see table 1 for phrasing of questions). We excluded euthanasia in order to concentrate on practices that are prominent in current professional and political discussions in the United States. Terminal sedation was defined as "diminishing consciousness to halt the experience of pain if a terminally ill patient has intractable pain despite aggressive analgesia". By this definition we chose to address the question of sedation without raising the related, but clinically separate, possibility of simultaneously withholding or withdrawing hydration and nutrition. Physician assisted suicide was defined as "intentionally prescribing a lethal dose of medication for a competent, terminally ill adult to ingest to end his or her life" $^{\prime \prime}$. Questions required responses on a five point Likert scale (strongly disagree, disagree, neutral, agree, strongly agree), with a sixth option of "not sure". The questionnaire requested demographic information including age, sex, religious affiliation, frequency of religious service attendance (options provided: weekly, monthly, less than monthly, none), and number of terminally ill patients given primary care in the preceding 12 months (options provided: $0,1-10$,

Abbreviations: ACP, American College of Physicians; PAS, physician assisted suicide. 
$11-25,26-50,>50)$. We explored religious factors because religion can be a significant source for ethical values ${ }^{29}$ and because prior literature has found religious factors to be some of the strongest and most consistent predictors of attitudes toward assisted suicide..$^{28-32}$ The survey instrument was pilot tested by 20 internists and refined.

\section{Participants}

Between February and April 1999, questionnaires were sent to all members of the Connecticut Chapter, American College of Physicians (ACP). A covering letter explained that the survey was being conducted under the auspices of the Connecticut ACP, that it was anonymous and voluntary, and that a stamped and coded return addressed postcard was enclosed and should be returned separately in order to track those who responded while maintaining the anonymity of their responses. A second questionnaire was sent to initial non-respondents. Our collaboration with ACP precluded any further attempts to solicit participation from persistent nonrespondents. No material inducements were offered. During the study period, assisting another person to commit suicide in Connecticut was prohibited as manslaughter in the second degree, ${ }^{34}$ and there was no legislation regarding PAS before the Connecticut State Legislature. The study was approved by the human investigation committee of Yale University School of Medicine and by the Governor's Council, Connecticut ACP.

\section{Statistical analysis and conceptual framework}

Frequencies, $\chi^{2}$ analyses, and multivariable logistic regression modelling were performed using Epi Info version 6 (Centers for Disease Control and Prevention, Atlanta, GA, USA) and SAS version 8 (SAS Institute Inc, Cary, NC, USA) statistical software. Dichotomous variables were created to facilitate analysis: agree and strongly agree were collapsed into agree; strongly disagree, disagree, neutral, and unsure were collapsed into not agree. By grouping neutral and unsure responses within not agree, we were able to make agreement the sharpest point of our analytic focus as we sought to understand characteristics of physicians who agree with (and therefore may be more willing to carry out) the end of life practices we studied (an alternate dichotomisation strategy was used for the analyses represented in table 2).

We categorised respondents in three groups along a three point spectrum of attitudes regarding aggressiveness in end of life care, as schematised by the stepwise hierarchy in figure 1: Group I (combining Groups IA and IB), those who did not agree with aggressive analgesia or terminal sedation; Group II, those who agreed with terminal sedation but not PAS; and

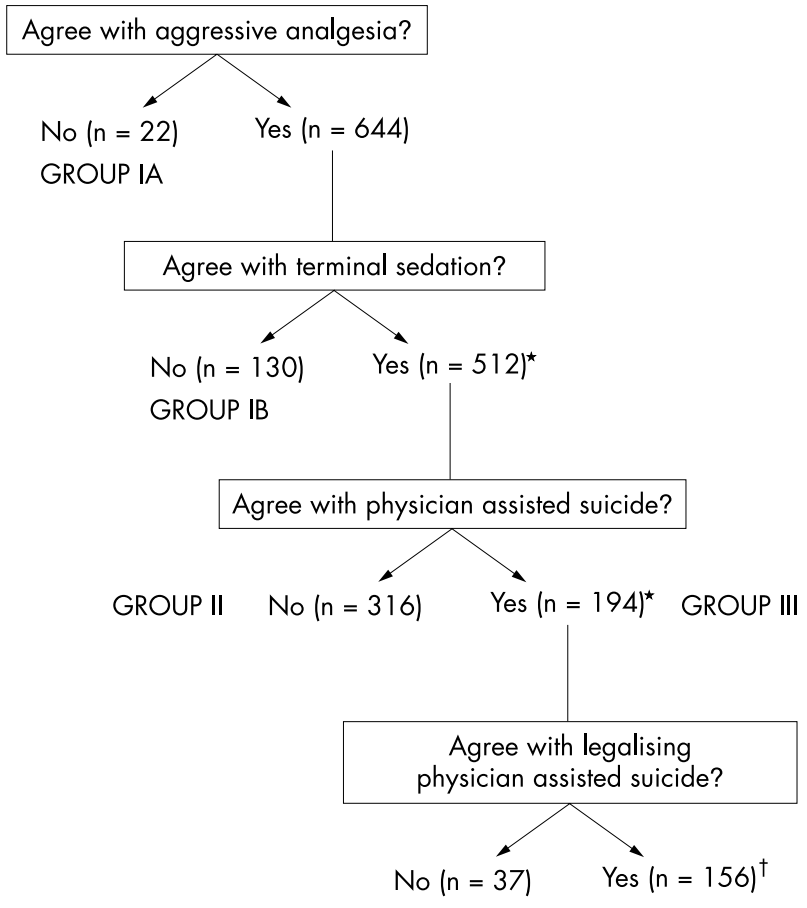

Figure 1 Stepwise hierarchical representation of physician attitudes towards aggressive palliation and physician assisted suicide (see table 1 for exact statement of questions). Yes collapses the responses of those who strongly agreed or agreed, and No collapses those who strongly disagreed, disagreed, were neutral, or unsure. ${ }^{*}$ There were two missing values at each of these levels. TThere was one missing value at this level.

Group III, those who agreed with terminal sedation and PAS. These groups were analysed for differences in demography, experience in terminal care, and religious background.

\section{RESULTS}

\section{Characteristics of the internists}

Of the 1456 questionnaires mailed to potential participants, five were returned because of address problems or death. There were 677 completed questionnaires (47\% response rate). Respondents to the second mailing did not differ significantly from the respondents to the initial mailing regarding attitudes toward terminal sedation, PAS, or in terms of their religious background or experience caring for terminally ill patients. Respondents' demographic data were

\begin{tabular}{|c|c|c|c|c|c|c|}
\hline \multirow[b]{2}{*}{ Question } & \multicolumn{6}{|c|}{ Response \% (n) } \\
\hline & $\begin{array}{l}\text { Strongly } \\
\text { disagree }\end{array}$ & Disagree & Neutral & Unsure & Agree & $\begin{array}{l}\text { Strongly } \\
\text { agree }\end{array}$ \\
\hline $\begin{array}{l}\text { In terminal illness, it is ethically } \\
\text { appropriate to increase analgesics } \\
\text { gradually to relieve pain, even if this } \\
\text { may unintentionally hasten death. }\end{array}$ & $0.5(2)$ & $1(6)$ & $2(12)$ & $0.5(2)$ & $35(236)$ & $61(408)$ \\
\hline $\begin{array}{l}\text { If a terminally ill patient has } \\
\text { intractable pain despite aggressive } \\
\text { analgesia, "terminal sedation" is } \\
\text { ethically appropriate. }\end{array}$ & $3(18)$ & $5(35)$ & $9(59)$ & $5(36)$ & $37(245)$ & $41(275)$ \\
\hline $\begin{array}{l}\text { PAS is ethically appropriate } \\
\text { in some circumstances. }\end{array}$ & $27(180)$ & $23(154)$ & 13 (92) & $4(28)$ & $23(153)$ & $10(66)$ \\
\hline $\begin{array}{l}\text { Some form of PAS should be } \\
\text { legalised in Connecticut. }\end{array}$ & $32(215)$ & $21(142)$ & $13(88)$ & $5(37)$ & 20 (134) & 9 (57) \\
\hline
\end{tabular}


similar to national and Connecticut ACP membership statistics (Cornog $\mathrm{M}$, personal communication), as follows: the mean age of our respondents was 51 years, compared with 47 years (nationally) and 48 years (Connecticut); $20 \%$ were women, compared with $21-26 \%$ (nationally) and $22-$ $24 \%$ (Connecticut) (ranges reflect extreme possibilities, given the unavailability of sex data from less than $5 \%$ of members); $85 \%$ of our respondents were graduates of US medical schools, compared with 75\% (nationally) and $71 \%$ (Connecticut). Forty one per cent of our respondents practiced only internal medicine, $32 \%$ only a subspecialty, and $25 \%$ both; less detailed data available for comparison show that $50 \%$ of ACP members nationally, and $51 \%$ in Connecticut, designate internal medicine as their primary specialty. The religious affiliations of our respondents were Jewish (27\%), Roman Catholic (24\%), none (26\%), nonCatholic Christian (17\%), other (2.4\%), Hindu (1.3\%), and Muslim (0.7\%); they attended religious services weekly $(28 \%)$, monthly $(14 \%)$, less than monthly $(36 \%)$, or not at all $(22 \%)$. Regarding the number of terminally ill patients to whom they provided primary care in the preceding 12 months: $6 \%$ had cared for $>50$ such patients, $6 \%$ had cared for $26-50,19 \%$ had cared for $11-25,46 \%$ had cared for $1-10$, and $23 \%$ had cared for none.

\section{Attitudes toward aggressive analgesia, terminal sedation, and PAS}

Table 1 shows that $96 \%$ of physicians supported the use of analgesics to relieve pain in terminal illness even at the risk of a hastened death, $78 \%$ supported the practice of terminal sedation, and approximately a third supported PAS. Figure 1 shows a stepwise hierarchical representation of response frequencies along a spectrum of aggressiveness. Twenty three per cent $(22+130)$ of respondents were in group I (did not agree with aggressive analgesia (1A) or terminal sedation (1B)), 47\% (316) in group II (agreed with terminal sedation but not PAS), and 29\% (194) in group III (agreed with terminal sedation and PAS). Differences between table 1 and figure 1 in the number of respondents who agreed to the latter three questions reflect the difference between reporting gross frequencies (table 1 ) and reporting the results hierarchically (fig 1).

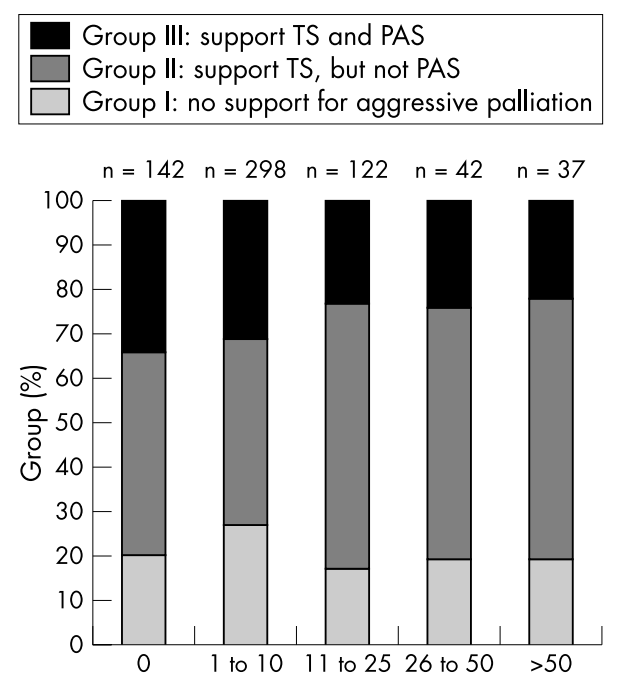

Figure 2 Proportional distribution of groups I, II, and III when stratified by self-reported number of terminally ill patients cared for in the past year. TS, terminal sedation; PAS, physician assisted suicide.
Distribution of groups according to clinical experience and religious practice

Figure 2 shows that those who reported more experience with terminally ill patients were relatively more likely to be in group II and less likely to be in group I or III $(p=0.02)$. Figure 3 shows that the more frequent a respondent's religious service attendance, the more likely they would be in group I or II and the less likely they would be in group III $(p<0.001)$. There were no statistically significant differences between groups with respect to sex or age. Among respondents in figure 1 who supported terminal sedation, multivariable logistic regression modelling revealed three variables that were independently associated with categorisation in group II as opposed to group III $(p<0.05)$ : experience caring for more than 10 terminally ill patients in the past year (OR 1.65, 95\% CI 1.04 to 2.63), Catholic or other Christian religious affiliation (OR 2.22, 95\% CI 1.42 to 3.46), and at least monthly religious service attendance (OR 2.77, $95 \%$ CI 1.75 to 4.41 ). For this regression model, the number of terminally ill patients cared for in the past year was divided to compare those who had cared for no patients or 1-10 patients with those who had cared for 11-25, 26-50, or more than 50 patients; likewise, frequency of religious service attendance was divided to compare those who attended services weekly or monthly with those who attended less than monthly or not at all. The significance of these three variables is further shown in table 2, in which attitudes toward assisted suicide were dichotomised by an alternate strategy: disagree and strongly disagree were collapsed into disagree and compared against not disagree (the combination of agree, strongly agree, neutral, and unsure). We applied this alternate dichotomisation for these analyses in order to focus on that group of physicians who explicitly agree with terminal sedation and explicitly disagree with assisted suicide. Table 2 shows that there was a "dose response" for frequency of religious service attendance and for the number of terminally ill patients cared for in the last 12 months.

\section{DISCUSSION}

The physicians we surveyed were widely supportive of aggressive palliative care in terminal illness: $97 \%$ favoured

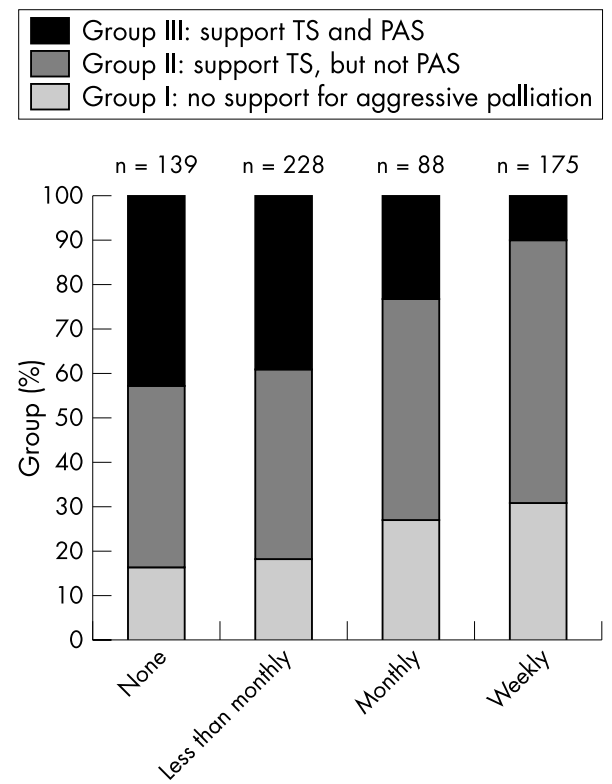

Figure 3 Proportional distribution of groups I, II, and III when stratified by frequency of religious service attendance. TS, terminal sedation; PAS, physician assisted suicide. 
Table 2 Disagreement with physician assisted suicide among physicians who agree with terminal sedation as stratified by religious affiliation, frequency of religious service attendance, and number of terminally ill patients cared for in the last 12 months

\begin{tabular}{lll}
\hline & $\begin{array}{l}\text { \% who disagree with } \\
\text { assisted suicide }\end{array}$ & p Value \\
\hline $\begin{array}{l}\text { Religious affiliation } \\
\text { No affiliation reported }\end{array}$ & 28 & \\
Jewish & 37 & $<0.001$ \\
Christian, non-Catholic & 59 & \\
$\quad$ Roman Catholic & 68 & \\
Frequency of religious service & & \\
attendance & 30 & $<0.001$ \\
$\quad$ None & 33 & \\
Less than monthly & 52 & \\
Monthly & 76 & \\
$\quad$ Weekly & & \\
Number of terminally ill patients \\
cared for in last 12 months & 40 & \\
$\quad 0$ & 39 & \\
$1-10$ & 54 & \\
$11-25$ & 62 & \\
$26-50$ & 68 & \\
$>50$ & & \\
\hline
\end{tabular}

the use of analgesics to control pain even at the risk of hastening death, and $78 \%$ favoured the use of terminal sedation as a treatment for refractory pain. These results are reassuring to those who believe that physicians who care for dying patients should be prepared to be therapeutically aggressive when the foremost goal of care is comfort. Support for aggressive palliation, however, was not generally accompanied by support for intentionally hastening death: $62 \%$ of physicians who supported terminal sedation did not support PAS. Our results suggest that most internists support aggressive palliation in terminal illness and, if they do, are likely to draw an ethical line between treatments that intend comfort and those, like assisted suicide, that also intend death.

We displayed the prevalence of such ethical line drawing by situating our results within a spectrum of aggressiveness in end of life care. The plurality of our respondents $(47 \%)$ were located in the middle (group II), supporting terminal sedation but not PAS. Physicians were more likely to be in this middle group if they reported more experience providing primary care to terminally ill patients or attended religious services more frequently (regardless of religious affiliation). These associations were strong and suggest that physician attitudes regarding terminal sedation and assisted suicide are shaped by clinical experience with dying patients and by religious beliefs.

It appears that most of the physicians we surveyed make a distinction between treatments that intend comfort and risk a hastened death and treatments that intend comfort and intend a hastened death. This suggests that the majority of our respondents would be likely to endorse something like the principle of double effect, ${ }^{20}{ }^{35}$ which attempts to justify foreseen but unintended side effects in aggressive palliation. This principle is used to support an action (for example, escalating morphine administration) that carries with it the possibility of an unintended, negative consequence (possible respiratory depression). The principle of double effect is taken seriously by those who believe that a physician's intention is important in determining whether or not an aggressive palliative intervention is morally acceptable. ${ }^{1-3} 13202136$ Although good intentions do not preclude the possibility of criminal recklessness, ${ }^{37}$ and well intentioned palliative care requires justifiable guidelines, ${ }^{3}$ the moral significance of intention has been supported by the US Supreme Court in justifying the legitimacy of aggressive palliation..$^{23}$

But the principle of double effect also has critics who question the relevance of intentions ${ }^{10}$ or believe that motivations for aggressive palliation are ambiguous. ${ }^{638}$ Although it is understandable that physicians may have mixed feelings as they keep company with their patients through prolonged suffering in terminal illness-and perhaps even experience a sense of relief when death ends afflictionit would be misleading to suggest that physicians cannot intend aggressive comfort without also intending to hasten death. If a patient continues to live after aggressive therapy has controlled symptoms, one need not suspect an additional motivation as long as there is no further upward titration of the palliative treatment. By contrast, if upward titration continues in spite of successful alleviation of symptoms, it would appear that death, too, is intended.

As important as the principle of double effect may be, the clinical basis of its relevance to aggressive palliative care warrants examination. Aggressive use of morphine is routinely described as the paradigm case for the double effects of analgesia and respiratory suppression. Agents that are used for sedation, like benzodiazepines, also may suppress respiratory drive. Although physiological concerns exist about the possibility that opioids and benzodiazepines may hasten death by suppressing respirations, there is a paucity of empirical data to support these concerns. Some argue that the concern about morphine's double effect is overstated and unsubstantiated, ${ }^{13} 1739$ and studies that have compared sedated and non-sedated patients in hospice have not found a difference in survival. ${ }^{14}{ }^{17-19}$ Even more provocative are suggestions that sedation towards the end of life may actually prolong life rather than hasten death, due to the dampening of increased metabolic demands caused by pain and distress in patients who are fragile. ${ }^{40}$ It would be reasonable to conclude that reference need not be made to foreseen but unintended consequences if those consequences are too improbable.

Our study had limitations. The absence of information from non-respondents raises the possibility of bias because of a response rate of $47 \%$, and although the demographic characteristics of our participants were representative of ACP membership, the results of this study may not be generalisable to physicians in other specialties, other states, or other professional organisations. Regarding religious background, however, the distribution of our participants' religious affiliations was very similar to other studies that have found religious variables to be strong predictors of attitudes toward PAS. ${ }^{30-33}$ Our study also relied on single item attitudinal queries that may not have reflected respondents' actual clinical practice.

If our results are representative of the attitudes of internists and other primary care providers who care for dying patients, does the public realise how many physicians may support the use of terminal sedation to treat refractory pain at the end of life? Given the dearth of empirical data regarding physician attitudes about terminal sedation, there is little empirical basis for assuming that patients are aware that the majority of physicians may be willing to place the highest priority on comfort, even at the expense of consciousness and at the risk of hastening death. In fact, there is some evidence to suggest that the public may not realise that aggressive treatments are available or legal. Over half of patients in an Oregon survey did not know that it is legal to administer analgesia to terminally ill patients if death might be hastened as a result. ${ }^{41}$ Assuming that support for terminal sedation among physicians is as prevalent as our study of internists suggests, patients and their families who fear the possibility of intolerable symptoms at the end of life 
should be reassured to know that most physicians appear to support a vigorous response to symptom control that truly puts comfort first.

\section{ACKNOWLEDGEMENTS}

We thank the two anonymous reviewers for their constructive comments.

\section{Authors' affiliations}

L C Kaldjian, Department of Internal Medicine, Yale University, New Haven, CT, USA

J F Jekel, Griffin Hospital, Derby, CT, USA

J L Bernene, American College of Physicians, CT, USA

G E Rosenthal, University of lowa, lowa City, IA, USA

$M$ Vaughan-Sarrazin, University of lowa, lowa City, IA, USA

T P Duffy, Yale University, New Haven, CT, USA

This study was funded in part by a Dissertation Fellowship to the principal investigator (LCK) from the Graduate School, Yale University, which had no role in the collection, analysis, interpretation, or publication of data.

Results from this study were presented at the Society of General Internal Medicine 25th Annual Meeting (Atlanta, GA, 3 May 2002) and published as an abstract ( $J$ Gen Intern Med 2002;17(Suppl 1):173).

\section{REFERENCES}

1 Chater S, Viola R, Paterson J, et al. Sedation for intractable distress in dyinga survey of experts. Palliat Med 1998;12:255-69.

2 Mount B. Morphine drips, terminal sedation, and slow euthanasia: definitions and facts, not anecdotes. J Palliat Care 1996;12:31-7.

3 Cherny NI, Portenoy RK. Sedation in the management of refractory symptoms: guidelines for evaluation and treatment. J Palliat Care 1994;10:31-8.

4 Cherny NI, Coyle N, Foley KM. The treatment of suffering when patients request elective death. J Palliat Care 1994;10:71-9.

5 Hardy J. Sedation in terminally ill patients. Lancet 2000;356:1866-7.

6 Quill TE, Byock IR. Responding to intractable terminal suffering: the role of terminal sedation and voluntary refusal of food and fluids. Ann Intern Med 2000;132:408-14.

7 Cowan JD, Walsh D. Terminal sedation in palliative medicine-definition and review of the literature. Support Care Cancer 2001:9:403-7.

8 Jansen LA, Sulmasy DP. Sedation, alimentation, hydration, and equivocation: careful conversation about care at the end of life. Ann Intern Med 2002;136:845-9.

9 Morita T, Tsuneto S, Shima Y. Proposed definitions for terminal sedation [lefter]. Lancet 2001:358:335-6.

10 Billings JA, Block SD. Slow euthanasia. J Palliat Care 1996;12:21-30.

11 Sulmasy DP, Ury WA, Ahronheim JC, et al. Palliative treatments of last resort and assisted suicide [letter]. Ann Intern Med 2000;133:562-3.

12 Orentlicher $\mathbf{D}$. The Supreme Court and physician-assisted suicide-rejecting assisted suicide but embracing euthanasia. N Eng J Med 1997;337:1236-9.

13 Portenoy RK. Morphine infusions at the end of life: the piffalls in reasoning from anecdote. J Palliat Care 1996;12:44-6.
14 Chiu T, Hu W, Lue B, et al. Sedation for refractory symptoms of terminal cancer patients in Taiwan. J Pain Symptom Manage 2001;21:467-72.

15 Fainsinger $\mathbf{R}$, Miller MJ, Bruera $E$, et al. Symptom control during the last week of life on a palliative care unit. J Palliat Care 1991;7:5-11.

16 Fainsinger RL, Waller A, Bercovici $M$, et al. A multicentre international study of sedation for uncontrolled symptoms in terminally ill patients. Palliat Med 2000; 14:257-65

17 Stone P, Phillips C, Spruyt O, et al. A comparison of the use of sedatives in a hospital support team and in a hospice. Palliat Med 1997:11:140-4.

18 Thorns A, Sykes N. Opioid use in last week of life and implications for end-oflife decision-making. Lancet 2000;356:398-9

19 Ventafridda V, Ripamonti C, deConno F, et al. Symptom prevalence and control during cancer patients' last days of life. J Palliat Care 1990;6:7-1 1.

20 Sulmasy DP, Pellegrino ED. The rule of double effect: Clearing up the double talk. Arch Intern Med 1999;159:545-50.

21 Foley KM. Competent care for the dying instead of physician-assisted suicide. N Engl J Med 1997;336:54-8.

22 Quill TE, Lo B, Brock DW. Palliative options of last resort: a comparison of voluntarily stopping eating and drinking, terminal sedation, physician-assisted suicide, and voluntary active euthanasia. JAMA 1997:278:2099-104.

23 Vacco $v$ Quill, 117 SCt 2293 (1997).

24 Meisel A, Snyder L, Quill T. Seven legal barriers to end-of-life care: myths, realities, and grains of truth. JAMA 2000;284:2495-501.

25 Burt RA. The Supreme Court speaks - not assisted suicide but a constitutional right to palliative care. N Engl J Med 1997;337:1234-6.

26 Luce JM, Alpers A. End-of-life care: what do the American courts say? Crit Care Med 2001;29(suppl):N40-5.

27 Quill TE, Meier DE, Block SD, et al. The debate over physician-assisted suicide: empirical data and convergent views. Ann Intern Med 1998;128:552-8.

28 Kaldjian LC, Wu BJ, Kirkpatrick JN, et al. Medical house officers' attitudes toward vigorous analgesia, terminal sedation, and physician-assisted suicide. Am J Hospice Palliat Care (in press).

29 Barnard D, Dayringer R, Cassel CK. Toward a person-centered medicine: religious studies in the medical curriculum. Acad Med 1995;70:806-13.

30 Meier DE, Emmons C-A, Wallenstein S, et al. A national survey of physicianassisted suicide and euthanasia in the United States. N Engl J Med 1998;338:1193-201

31 Bachman GB, Ascser KH, Doukas DJ, et al. Attitudes of Michigan physicians and the public toward legalizing physician-assisted suicide and voluntary euthanasia. N Engl J Med 1996;334:303-9.

32 Lee MA, Nelson HD, Tilden VP, et al. Legalizing assisted suicide-views of physicians in Oregon. N Engl J Med 1996;334:310-15.

33 Emanuel EJ, Fairclough DL, Daniels ER, et al. Euthanasia and physicianassisted suicide: attitudes and experiences of oncology patients, oncologists, and the public. Lancet 1996;347:1805-10.

34 Connecticut General Statutes, Section 53a-56 (available at http:// www.cga.state.ct.us/2003/pub/Chap952.htm \#Sec53a-56.htm).

35 Quill TE, Dresser R, Brock DW. The rule of double effect-a critique of its role in end-of-life decision making. N Engl J Med 1997;337:1768-71.

36 Hawryluck L. Neuromuscular blockers - a means of palliation? J Med Ethics 2002;28:170-2.

37 Cantor NL, Thomas GC. Pain relief, acceleration of death, and criminal law. Kennedy Inst Ethics J 1996:6:107-28.

38 Quill TE, Lee BC, Nunn S. Palliative treatments of last resort: choosing the least harmful alternative. Ann Intern Med 2000;132:488-93.

39 Fohr SA. The double effect of pain medication: separating myth from reality. J Palliat Med 1998;1:315-28.

40 Lynn J. Terminal sedation [letter]. N Engl J Med 1998;338:1230.

41 Silveira MJ, DiPiero A, Gerrity MS, et al. Patients' knowledge of options at the end of life: ignorance in the face of death. JAMA 2000;284:2483-8. 